\title{
National and State-Specific Unit Sales and Prices for Electronic Cigarettes, United States, 2012-2016
}

\author{
Teresa W. Wang, PhD, MS ${ }^{1}$; Ellen M. Coats, $\mathrm{MS}^{2}$; Doris G. Gammon, $\mathrm{MS}^{2}$; Brett R. Loomis, $\mathrm{MS}^{2}$; \\ Nicole M. Kuiper, $\mathrm{MPH}^{1}$; Todd Rogers, $\mathrm{PhD}^{2}$; Brian A. King, PhD, $\mathrm{MPH}^{1}$
}

\begin{abstract}
Accessible Version: www.cdc.gov/pcd/issues/2018/17_0555.htm
Suggested citation for this article: Wang TW, Coats EM, Gammon DG, Loomis BR, Kuiper NM, Rogers T, et al. National and State-Specific Unit Sales and Prices for Electronic Cigarettes, United States, 2012-2016. Prev Chronic Dis 2018;15:170555. DOI: https://doi.org/10.5888/pcd15.170555.
\end{abstract}

\section{PEER REVIEWED}

\section{Abstract}

\section{Introduction}

Few studies have explored patterns of electronic cigarette (e-cigarette) sales and prices by product type over time. We used US retail scanner data to assess national and state-specific trends in e-cigarette unit sales and prices for 4 product types sold from 2012 through 2016.

\section{Methods}

Using retail scanner data from the 48 contiguous states and Washington, DC, for convenience stores; supermarkets; mass merchandisers; drug, dollar, and club stores; and military commissaries, we assessed data on monthly unit sales and inflation-adjusted prices by 4 products (rechargeables, disposables, prefilled cartridges, and e-liquids) sold during the 5 -year study period. We evaluated national and state trends by using Joinpoint regression $(P<.05)$.

\section{Results}

From 2012 through 2016, average national monthly unit sales significantly increased for all products, while average monthly prices of rechargeables, disposables, and prefilled cartridges significantly decreased. In 2016, prefilled cartridges had the highest average sales (766 units per 100,000 people) and the lowest average price (\$14.36 per unit). By state, average monthly sales signific- antly increased for at least 1 of 4 e-cigarette products in all 48 states and Washington, DC. However, during the same period, average monthly prices significantly decreased in 39 states for rechargeables, in 31 states for disposables, in 20 states for prefilled cartridges, and in 8 states for e-liquids.

\section{Conclusion}

Overall, US e-cigarette unit sales generally increased as product prices decreased. These findings demonstrate the rapidly evolving landscape of US e-cigarette retail marketplace. Ongoing surveillance of e-cigarette unit sales and price is critical for informing and evaluating evidence-based tobacco control strategies.

\section{Introduction}

Electronic cigarettes (e-cigarettes) are a diverse product class of battery-powered devices designed to deliver a combination of nicotine, flavorings, and other additives via an inhaled aerosol (1). Since their entry into the US marketplace in 2007, e-cigarettes have rapidly evolved in product design, marketing, and availability $(2,3)$. In 2014, researchers identified more than 460 e-cigarette brands and 7,700 e-liquid flavors (4). These products are now widely distributed through traditional retail outlets, vape shops, and online retailers (5).

This surge in product availability coincided with increased e-cigarette use, particularly among current and former adult smokers (6). E-cigarette use increased $900 \%$ among US high school students from 2011 to 2015, and e-cigarettes surpassed conventional cigarettes as the most commonly used tobacco product among this group (7). The prominent use of e-cigarettes among US youth has been attributed in part to the heavy marketing of these products with youth-resonating themes, as well as the widespread availability of youth-appealing flavors $(7,8)$.

As the tobacco product retail landscape continues to evolve, market surveillance using objective retail sales data can complement 
self-reported measures to enhance our understanding of consumption patterns and assess the impact of tobacco product regulations (9-13). Proportionate sales of e-cigarettes have been small relative to sales of other tobacco products, especially combustible products. At the end of 2015, cigarette sales were 64 times higher than e-cigarette sales in convenience stores and 73 times higher in "all other outlets combined" (10). However, retail sales data that document the growth in consumption of these products warrants continued monitoring $(4,5)$. To date, few studies have explored ecigarette sale and price patterns at the national and state levels in the United States $(10,13)$. Furthermore, the extent of more recent e-cigarette sales and price trends has not been examined, and no study has provided a nuanced assessment by product type at both levels. We addressed these gaps by using retail scanner data to assess overall national and state trends in e-cigarette prices and unit sales for 4 product types during the 5-year period from 2012 through 2016.

\section{Methods}

We acquired data on Universal Product Code (UPC) retail sales for e-cigarette products from The Nielsen Company (www.nielsen.com/us/en.html). These data include data on sales from convenience stores (franchise, chain, and independent convenience stores that may or may not sell gasoline) and all other outlets combined (a category that includes mass merchandisers; supermarkets; drug, dollar, and club stores; and military commissaries). Sales are reported in approximately monthly (4-week) aggregates; these period-to-period changes are referred to as monthly changes.

Data were obtained for sales occurring from January 12, 2012, through January 7, 2017. Given that the final 4-week period occurred primarily in 2016 , the overall study period is referred to as "2012-2016" hereinafter. We analyzed combined sales at convenience stores and all other outlets combined across the 48 contiguous states and Washington, DC. Sales projections for Alaska and Hawaii were not available from Nielsen and, thus, were not included in our study.

\section{Measures}

The sales data include detailed information on the type of e-cigarette device, brand, flavor, strength, and count per item. Using UPC-specific information, we classified items into 4 mutually exclusive products: 1) rechargeable e-cigarette devices (rechargeables), 2) disposable e-cigarette devices (disposables), 3) disposable cartridges prefilled with e-liquid (prefilled cartridges), and 4) e-liquid bottles for filling reusable cartridges (e-liquids).
Items associated with the descriptor "KIT" or those containing at least one refill, rechargeable battery, and battery charger were classified as rechargeables. Disposables include single-use products that cannot be recharged or refilled. E-cigarette accessories, including lanyards and replacement parts sold without e-liquid, were excluded from our analysis. We reviewed brand websites when we could not determine the product from the information provided in the Nielsen data set ( $\sim 5 \%$ of UPCs).

\section{Analysis}

We calculated sales volume by using standardized unit sales. Within each product category, we standardized unit sales to represent the most common package size for each product type. A standardized unit, henceforth "unit," equals 1 rechargeable, 1 disposable, 5 prefilled cartridges, or 1 e-liquid bottle. For example, raw unit sales for a UPC indicating a pack of 10 prefilled cartridges were multiplied by 2 to reflect the equivalent number of units sold as a pack of 5 . Unit sales were aggregated to produce total monthly sales by product, geography, and time period. We tabulated all national and state unit sales as sales rates of unit sales per 100,000 people (all ages), which was calculated by using respective population estimates from the US Census Bureau (14).

Average prices by product were calculated by using adjusted dollars and nonstandardized units. To generate inflation-adjusted dollar sales, we indexed dollar sales to the 2016 Consumer Price Index from the US Bureau of Labor Statistics (15). Prices were then calculated by using only items sold in the most common package size for each product. For example, only prefilled cartridges that were sold in a pack of 5 were included in price calculations for prefilled cartridges. Although standardizing a pack of 10 prefilled cartridges to represent 2 packs of 5 is appropriate for reflecting sales volume, these sales were excluded from price calculations to avoid the introduction of bias due to discounts associated with buying in bulk.

We evaluated the overall trend from 2012 through 2016 by using Joinpoint models that controlled for autocorrelation to quantify and test the direction and significance $(P<.05)$ of the average monthly percentage change (AMPC) (16). Additionally, for 2012 and 2016 we determined an average monthly sales rate and assessed year-to-year percentage change during the study period. Although the national data indicated e-liquid sales began in mid2013, e-liquid sales did not begin until early 2014 in some states. Therefore, the study period for e-liquid sales includes only periods from 2014 through 2016 that had non-zero sales.

\footnotetext{
The opinions expressed by authors contributing to this journal do not necessarily reflect the opinions of the U.S. Department of Health and Human Services, the Public Health Service, the Centers for Disease Control and Prevention, or the authors' affiliated institutions.
} 


\section{Results}

Nationally, the average monthly e-cigarette sales rate as summed across all product types sold (ie, acknowledging no observable eliquid sales in 2012) increased by $132 \%$, from 667 units per 100,000 people in 2012 to 1,547 units per 100,000 people in 2016 (Table 1). Unit sales increased by $154 \%$ for rechargeables (AMPC $=1.7), 27 \%$ for disposables $(\mathrm{AMPC}=1.0), 256 \%$ for prefilled cartridges $(\mathrm{AMPC}=2.4)$, and $64 \%$ for e-liquids $(\mathrm{AMPC}=5.9)$. The average monthly sales rate was highest in 2016 among prefilled cartridges (766 units), followed by disposables (445 units), rechargeables (259 units), and e-liquids (77 units).

Despite overall sales growth, sales fluctuated across time by product type (Figure 1). Specifically, sales of rechargeables, prefilled cartridges, and e-liquids grew relatively steadily over time, while sales for disposables were less consistent. In the final 4 weeks of the study period, prefilled cartridge sales rate peaked at more than 856 units. In contrast, sales of disposables increased sharply in late 2012 before peaking in 2013 as the product with the highest sales rate. Disposables later decreased in sales from 2014 to 2016 .



Figure 1. Unit sales of e-cigarettes by product type and by 4-week periods, United States 2012-2016. One unit is equal to 1 rechargeable, 1 disposable, 5 prefilled cartridges, or 1 e-liquid bottle.

\section{State sales trends}

Each of the 48 states and Washington, DC, had significant average monthly sales growth for at least 1 e-cigarette product type (Table 1). Ten states (Maine, New Hampshire, New Jersey, New York, Michigan, South Dakota, Delaware, Florida, Arizona, California) and Washington, DC, had significant average monthly sales growth for all 4 product types. Between 2012 and 2016, the most prominent increases were observed in South Dakota, where scanner data indicated a relative percentage increase of $1,110 \%$ for rechargeables $(\mathrm{AMPC}=5.1)$ and $4,218 \%$ for prefilled cartridges $(\mathrm{AMPC}=6.8)$; and in Illinois, where data indicated a relative percentage increase of $430 \%$ for disposables $(\mathrm{AMPC}=3.6)$. Between
2014 and 2016, Minnesota had the highest relative increase for eliquid sales at $636 \%(\mathrm{AMPC}=15.3)$. In 2016, the highest average monthly sales rate occurred in New Hampshire for rechargeables (622 units), Illinois for disposables (1,527 units), South Dakota for prefilled cartridges (1,641 units), and West Virginia for e-liquids (258 units).

\section{National price trends}

Nationally, average e-cigarette prices decreased by $48 \%$ for rechargeables $(\mathrm{AMPC}=-1.2), 14 \%$ for disposables $(\mathrm{AMPC}=$ $-0.2)$, and $12 \%$ for prefilled cartridges $(\mathrm{AMPC}=-0.4)$ from 2012 through 2016 (Table 2). E-liquid prices, however, did not significantly change across the study period. In 2016, the average e-cigarette price was highest for a unit of prefilled cartridges (\$14.36), followed by rechargeables (\$10.33), disposables (\$8.01), and e-liquids $(\$ 6.83)$.

Similar to national trends in unit sales, national trends in e-cigarette prices fluctuated over time (Figure 2). Rechargeable e-cigarette prices fluctuated during the beginning of the study period, peaking in early 2013 around $\$ 27$. Prices then decreased by more than 55\% to approximately $\$ 12$ in October 2014, before decreasing more steadily throughout 2015 and 2016. Despite fluctuations shortly after they first appeared in convenience stores and all other outlets combined, e-liquid prices averaged approximately $\$ 7$ from late 2013 through the end of the study period.



Figure 2. Average prices of e-cigarettes by product type and by 4-week periods, United States 2012-2016. Average prices were calculated by using inflation-adjusted dollars (2016) and raw unit sales. Only items sold in the most common package size for each product were included in average price calculations.

\section{State price trends}

From 2012 through 2016, average monthly e-cigarette prices significantly decreased in 39 states for rechargeables, 31 states for disposables, 20 states for prefilled cartridges, and 8 states for e-liquids. In contrast, we found significant average monthly price in-

The opinions expressed by authors contributing to this journal do not necessarily reflect the opinions of the U.S. Department of Health and Human Services, the Public Health Service, the Centers for Disease Control and Prevention, or the authors' affiliated institutions. 
creases in 1 state (Pennsylvania) and Washington, DC, for disposables, 2 states (Wyoming and Wisconsin) for prefilled cartridges, and 5 states (Arkansas, Florida, Louisiana, Texas, Wyoming) and Washington, DC, for e-liquids.

In 2016, West Virginia had the lowest average monthly sales price for rechargeables (\$8.38), Illinois for disposables (\$6.20), Oklahoma for prefilled cartridges (\$10.43), and Alabama for e-liquids (\$5.32). The highest average unit prices for each product type in 2016 were in Washington, DC, where monthly average prices per unit were $\$ 18.43$ for rechargeables, $\$ 14.75$ for disposables, \$20.58 for prefilled cartridges, and \$10.19 for e-liquids.

\section{Discussion}

From 2012 through 2016, e-cigarette unit sales in the United States significantly increased for all assessed product types, including rechargeables, disposables, prefilled cartridges, and e-liquids. At the state level, monthly unit sales significantly increased for at least 1 product type in all 48 states and Washington, DC. During the same period, national e-cigarette prices significantly decreased for all product types with the exception of e-liquids, which increased in price in 5 states and Washington, DC. Taken together, these findings underscore the rapidly evolving landscape of the US e-cigarette retail marketplace, with decreases in unit price accompanying increases in sales trends overall. Furthermore, prominent shifts occurred by product type, with prefilled cartridges having the highest average sales and the lowest average price in 2016.

Variations in US e-cigarette sales and prices have persisted since the first national and state assessment of their retail sales at convenience stores and all other outlets combined; during 2012-2013, the revenue of e-cigarettes in those retail channels increased by $320 \%$ for disposables, $72 \%$ for starter kits, and $82 \%$ for prefilled cartridges (13). Our study, however, found that disposable products no longer dominate e-cigarette sales in these retail channels: rechargeables had the largest relative percentage increase in sales from 2012 through 2016. Furthermore, prefilled cartridge sales increased substantially by more than $256 \%$ through 2016 , surpassing all other product types to become the most commonly sold unit of e-cigarette products in convenience stores and all other outlets combined. Additionally, e-liquids had rapid sales growth, with an average monthly percentage increase of $5.9 \%$ in national unit sales during 2014-2016. These findings are generally consistent with industry reports indicating that disposables comprise a declining proportion of e-cigarette retail sales $(9,17)$. This decline may reflect an underlying shift in product preference among consumers; established e-cigarette users who are current or former smokers, for instance, can graduate to using more customizable devices featuring open systems $(1,18)$.

Price gaps for e-cigarette devices have narrowed over time. During the 4-week period ending on June 29, 2013, the national average price of rechargeables (\$25.69) was more than 3 times the average price of disposables $(\$ 9.26)$. Rechargeable prices have since plummeted; in 2016, the average price difference between a rechargeable unit and a disposable unit was less than \$2. In contrast, although the average price of both prefilled cartridges and e-liquids decreased, a unit of prefilled cartridges was approximately twice the average price of a bottle of e-liquid throughout the study period. Overall, the increase in e-cigarette sales and decrease in price is consistent with previous studies demonstrating that e-cigarette sales are responsive to their own price changes (19). These trends suggest that, if e-cigarette prices continue to decrease, their sales may also continue to rise. However, other factors, such as the pricing and consumption of other conventional or newer tobacco products, will affect e-cigarette demand (1).

Sales data at the federal and subnational levels can help inform and evaluate efforts to regulate e-cigarettes at the national, state, and local levels. In 2009, the Family Smoking Prevention and Tobacco Control Act (20) gave the US Food and Drug Administration (FDA) the authority to regulate the manufacturing, distribution, and marketing of cigarettes, roll-your-own cigarette tobacco, and smokeless tobacco sold in the United States. In May 2016, the FDA subsequently issued a deeming rule to extend its authority over all tobacco products, including e-cigarettes and their components and parts (eg, cartridges) (21).

The Family Smoking Prevention and Tobacco Control Act preserves state and local authority over implementing certain regulations in addition to some actions not otherwise covered by the Act that are expressly under the purview of state and local authority. These actions include restricting tobacco use in public places, levying taxes on tobacco products, raising the age of sale above 18 , and restricting sales by certain retailers $(1,21)$. With regard to e-cigarettes, some states and localities have implemented strategies to both minimize the potential harms of e-cigarette consumption at the population level, particularly among youth and young adults, and to maximize any potential benefits for current adult smokers (1,2). As of June 2017, 46 states and Washington, $\mathrm{DC}$, have minimum legal age restrictions on the purchase of e-cigarettes; 15 states require a retail license to sell e-cigarettes over the counter; 8 states (California, Delaware, Hawaii, New Jersey, North Dakota, Oregon, Utah, Vermont), Washington, DC, and Puerto Rico have comprehensive smoke-free indoor air laws that prohibit smoking and using e-cigarettes in indoor areas of private worksites, restaurants, and bars; and 7 states (California, Kansas, Louisiana, Minnesota, North Carolina, Pennsylvania, West Virgin-

\footnotetext{
The opinions expressed by authors contributing to this journal do not necessarily reflect the opinions of the U.S. Department of Health and Human Services, the Public Health Service, the Centers for Disease Control and Prevention, or the authors' affiliated institutions.
} 
ia) and Washington, DC, have enacted e-cigarette taxation policies $(22,23)$. Although the long-term impact of these population-based strategies on e-cigarette sales in US retail outlets continues to be assessed, cross-sectional audits from nationally representative samples of tobacco retailers suggest that e-cigarettes are more likely to be available in retail outlets in areas with lower e-cigarette prices and less comprehensive smoke-free air policies (24). Moreover, the US Surgeon General indicated that higher prices and comprehensive smoke-free air policies are among the most effective methods to prevent initial use of conventional tobacco products among adolescents and young adults (2).

Our study indicates that the average price across all e-cigarette types in 2016 was highest in Washington, DC, which may be attributable, in part, to the city's taxation of e-cigarettes at $67 \%$ of the wholesale price (25). In contrast, states with the lowest average prices for rechargeables (West Virginia), disposables (Illinois), prefilled cartridges (Oklahoma), and e-liquids (Alabama) do not currently have state e-cigarette tax policies. Previous research suggests that a $10 \%$ increase in the price of e-cigarettes would reduce the sales of disposable and rechargeable e-cigarettes by approximately $12 \%$ and $19 \%$, respectively (19). Thus, the continued monitoring of e-cigarette sales data in the context of these evolving strategies may inform the implementation and sustainment of related tobacco control policies and practices.

Our study has several limitations. First, Nielsen's projection methods are proprietary. However, Nielsen scanner data are widely used in academic and marketing research, and previous sales estimates are consistent with US Treasury and securities analyst reports $(10,17,26)$. Second, these data are derived from product sales at traditional tobacco retail outlets and do not include sales from tobacco specialty or vape shops or the internet because data for these venues are not commercially available (1); these omitted outlets were estimated to account for a majority of the overall electronic nicotine delivery system market in 2017 (17). Third, our study may not have captured the full range of data on e-cigarette products currently available on the US market given that more advanced products, such as tank-style systems, are predominantly sold in vape shops and on the internet $(27,28)$. Finally, our study could not account for coupons or promotions applied at the point of sale.

From 2012 through 2016, e-cigarette unit sales in the United States generally increased as product prices decreased. Moreover, notable shifts in sales occurred by product type; prefilled cartridges, in particular, had the highest average unit sales and the highest average unit price in 2016. Given that e-cigarettes have a range of potential impacts on individual and population health (2), ongoing surveillance of e-cigarette sales is important to help inform tobacco control policies and practices. Strategies at the na- tional, state, and local level, including proven population-based tobacco interventions $(1,2,29)$, will be critical to minimize harms and maximize any potential benefits that e-cigarettes could have on individual and population-level health $(1,2)$.

\section{Acknowledgments}

Support was provided by the Centers for Disease Control and Prevention, in part, through contracts 200-2014-F-6122, 200-2016-F92371, and 200-2013-M-53964B. Editorial assistance was provided by Amy Reff and Justin Faerber, RTI. No copyrighted materials, surveys, instruments, or tools were used in this study. The findings and conclusions in this report are those of the authors and do not necessarily represent the official position of the Centers for Disease Control and Prevention.

\section{Author Information}

Corresponding Author: Teresa W. Wang, PhD, MS, Office on Smoking and Health, National Center for Chronic Disease Prevention and Health Promotion, Centers for Disease Control and Prevention, 4770 Buford Hwy, MS S107-7, Atlanta, GA 30341. Telephone: 404-498-1502. Email: yxn7@cdc.gov.

Author Affiliations: ${ }^{1}$ Office on Smoking and Health, National Center for Chronic Disease Prevention and Health Promotion, Centers for Disease Control and Prevention, Atlanta, Georgia. ${ }^{2}$ Center for Health Policy Science and Tobacco Research, RTI International, Research Triangle Park, North Carolina.

\section{References}

1. US Department of Health and Human Services. E-cigarette use among youth and young adults: a report of the Surgeon General. Atlanta (GA): US Department of Health and Human Services, Centers for Disease Control and Prevention, National Center for Chronic Disease Prevention and Health Promotion, Office on Smoking and Health; 2016.

2. US Department of Health and Human Services. The health consequences of smoking - 50 years of progress: a report of the Surgeon General. Atlanta (GA): US Department of Health and Human Services, Centers for Disease Control and Prevention, National Center for Chronic Disease Prevention and Health Promotion, Office on Smoking and Health; 2014.

3. Grana R, Benowitz N, Glantz SA. E-cigarettes: a scientific review. Circulation 2014;129(19):1972-86.

4. Zhu SH, Sun JY, Bonnevie E, Cummins SE, Gamst A, Yin L, et al. Four hundred and sixty brands of e-cigarettes and counting: implications for product regulation. Tob Control 2014;23(Suppl 3):iii3-9.

The opinions expressed by authors contributing to this journal do not necessarily reflect the opinions of the U.S. Department of Health and Human Services, the Public Health Service, the Centers for Disease Control and Prevention, or the authors' affiliated institutions. 
5. Giovenco DP, Hammond D, Corey CG, Ambrose BK, Delnevo CD. E-cigarette market trends in traditional US retail channels, 2012-2013. Nicotine Tob Res 2015;17(10):1279-83.

6. King BA, Patel R, Nguyen KH, Dube SR. Trends in awareness and use of electronic cigarettes among US adults, 2010-2013. Nicotine Tob Res 2015;17(2):219-27.

7. Singh T, Arrazola RA, Corey CG, Husten CG, Neff LJ, Homa $\mathrm{DM}$, et al. Tobacco use among middle and high school students - United States, 2011-2015. MMWR Morb Mortal Wkly Rep 2016;65(14):361-7.

8. Ambrose BK, Day HR, Rostron B, Conway KP, Borek N, Hyland A, et al. Flavored tobacco product use among US youth aged 12-17 years, 2013-2014. JAMA 2015; 314(17):1871-3.

9. Day HR, Ambrose BK, Schroeder MJ, Corey CG. Point-ofsale scanner data for rapid surveillance of the e-cigarette market. Tob Regul Sci 2017;3(3):325-32.

10. Marynak KL, Gammon DG, King BA, Loomis BR, Fulmer EB, Wang TW, et al. National and state trends in sales of cigarettes and e-cigarettes, US, 2011-2015. Am J Prev Med 2017;53(1):96-101.

11. Rogers T, Brown EM, Mccrae TM, Gammon DG, Eggers ME, Watson $\mathrm{K}$, et al. Compliance with a sales policy on flavored non-cigarette tobacco products. Tob Regul Sci 2017;3(Suppl 1):84-93.

12. Gammon DG, Loomis BR, Dench DL, King BA, Fulmer EB, Rogers T. Effect of price changes in little cigars and cigarettes on little cigar sales: USA, Q4 2011-Q4 2013. Tob Control 2016;25(5):538-44.

13. Loomis BR, Rogers T, King BA, Dench DL, Gammon DG, Fulmer EB, et al. National and state-specific sales and prices for electronic cigarettes — US, 2012-2013. Am J Prev Med 2016;50(1):18-29.

14. US Census Bureau, Population Division. Annual estimates of the resident population: April 1, 2010 to July 1, 2016. http:// factfinder2.census.gov. Accessed June 4, 2018.

15. US Department of Labor, US Bureau of Labor Statistics. BLS data viewer. 2017. https://beta.bls.gov/dataViewer/view/ t i m e s e r i e s / C U U R $0000 \mathrm{~S} \mathrm{~A} 0$; j s e s s i o n i d= FBC120432C41AEF5D566386AA906DFB0.tc_instance6. Accessed July 18, 2017.

16. National Cancer Institute. Joinpoint regression program, version 4.0. December, 2012. http://surveillance.cancer.gov/ joinpoint/. Accessed September 7, 2017.

17. Herzog B. Nielsen: tobacco "all channel" data through August 12, 2017. Charlotte, NC: Wells Fargo Securities, LLC; 2017.
18. Farsalinos KE, Romagna G, Tsiapras D, Kyrzopoulos S, Voudris V. Characteristics, perceived side effects and benefits of electronic cigarette use: a worldwide survey of more than 19,000 consumers. Int J Environ Res Public Health 2014; 11(4):4356-73.

19. Huang J, Tauras J, Chaloupka FJ. The impact of price and tobacco control policies on the demand for electronic nicotine delivery systems. Tob Control 2014;23(Suppl 3):iii41-7.

20. US Department of Health and Human Services, US Food and Drug Administration. Family Smoking Prevention and Tobacco Control Act - an overview. https://www.fda.gov/ TobaccoProducts/GuidanceComplianceRegulatoryInformation/ ucm246129.htm. Accessed May 23, 2018.

21. US Department of Health and Human Services, US Food and Drug Administration. Extending authorities to all tobacco products, including 435 e-cigarettes, cigars, and hookah. Washington (DC): US Department of Health and Human Services, US Food and Drug Administration; 2016. http:// w w w . fda.gov/ T ob a c co Product s/ L a b e ling/ RulesRegulationsGuidance/ucm388395.htm. Accessed August 3, 2017.

22. Centers for Disease Control and Prevention. STATE system ecigarette fact sheet [Internet]. Washington: US Department of Health and Human Services, Centers for Disease Control and Prevention; 2017. https://chronicdata.cdc.gov/Legislation/ STATE-System-E-Cigarette-Fact-Sheet/qte6-7jwd. Accessed August 18, 2017.

23. Centers for Disease Control and Prevention. STATE system ecigarette legislation - tax. Washington (DC): US Department of Health and Human Services, Centers for Disease Control and Prevention; 2017. https:/chronicdata.cdc.gov/Legislation/ CDC-STATE-System-E-Cigarette-Legislation-Tax/kwbr-syv2. Accessed August 16, 2017.

24. Rose SW, Barker DC, D’Angelo H, Khan T, Huang J, Chaloupka FJ, et al. The availability of electronic cigarettes in U.S. retail outlets, 2012: results of two national studies. Tob Control 2014;23(Suppl 3):iii10-6.

25. Office of Tax and Revenue. Vapor products subject to excise tax effective October 1, 2015; exempt from sales tax. Washington (DC): Office of Tax and Revenue; 2015. https:// otr.cfo.dc.gov/release/vapor-products-subject-excise-taxeffective-october-1-2015-exempt-sales-tax. Accessed August 9, 2017.

26. US Department of the Treasury. Alcohol and Tobacco Tax and Trade Bureau. Statistical report - tobacco. Reporting period: December 2015. TTB S 5210-12-2015. 2016. https://ttb.gov/ statistics12tobacco.pdf. Accessed August 8, 2017.

27. Lee YO, Kim AE. 'Vape shops' and 'e-cigarette lounges' open across the USA to promote ENDS. Tob Control 2015; 24(4):410-2.

\footnotetext{
The opinions expressed by authors contributing to this journal do not necessarily reflect the opinions of the U.S. Department of Health and Human Services, the Public Health Service, the Centers for Disease Control and Prevention, or the authors' affiliated institutions.
} 
28. Sussman S, Baezconde-Garbanati L, Garcia R, Barker DC, Samet JM, Leventhal A, et al. Commentary: forces that drive the vape shop industry and implications for the health professions. Eval Health Prof 2016;39(3):379-88.

29. Centers for Disease Control and Prevention. Best practices for comprehensive tobacco control programs - 2014. Washington (DC): US Department of Health and Human Services, Centers for Disease Control and Prevention; 2014. http://www.cdc.gov/ tobacco/stateand community/best_practices/ index.htm?source=govdelivery. Accessed August 25, 2017. 


\section{Tables}

Table 1. E-Cigarette Unit Sales by Product Type, United States, 2012-2016

\begin{tabular}{|c|c|c|c|c|c|c|c|c|c|c|c|c|c|c|c|c|}
\hline \multirow[b]{3}{*}{ State } & \multicolumn{4}{|c|}{ Rechargeables } & \multicolumn{4}{|c|}{ Disposables } & \multicolumn{4}{|c|}{ Prefilled Cartridges } & \multicolumn{4}{|c|}{ E-Liquids } \\
\hline & \multicolumn{2}{|c|}{$\begin{array}{l}\text { Monthly Unit } \\
\text { Sales }^{\mathrm{a}}\end{array}$} & \multirow{2}{*}{$\underset{\%}{\text { Change, }}$} & \multirow[b]{2}{*}{$\mathrm{AMPC}^{\mathrm{b}}$} & \multicolumn{2}{|c|}{$\begin{array}{l}\text { Monthly Unit } \\
\text { Sales }\end{array}$} & \multirow{2}{*}{$\begin{array}{c}\text { Change, } \\
\%\end{array}$} & \multirow[b]{2}{*}{ AMPC $^{b}$} & \multicolumn{2}{|c|}{$\begin{array}{l}\text { Monthly Unit } \\
\text { Sales }^{\mathrm{a}}\end{array}$} & \multirow{2}{*}{$\underset{\%}{\text { Change, }}$} & \multirow[b]{2}{*}{$\mathrm{AMPC}^{\mathrm{b}}$} & \multicolumn{2}{|c|}{$\begin{array}{l}\text { Monthly Unit } \\
\text { Sales }^{\text {a }}\end{array}$} & \multirow{2}{*}{$\begin{array}{c}\text { Change, } \\
\%^{\mathrm{d}}\end{array}$} & \multirow[b]{2}{*}{ AMPC $^{b}$} \\
\hline & 2012 & 2016 & & & 2012 & 2016 & & & 2012 & 2016 & & & 2014 & 2016 & & \\
\hline All & 102 & 259 & 154 & $1.7^{\mathrm{C}}$ & 350 & 445 & 27 & $1.0^{c}$ & 215 & 766 & 256 & $2.4^{\mathrm{c}}$ & 47 & 77 & 64 & $5.9^{c}$ \\
\hline \multicolumn{17}{|c|}{ Northeast } \\
\hline CT & 60 & 103 & 72 & 0 & 266 & 553 & 108 & 1.2 & 155 & 453 & 192 & $1.1^{\mathrm{c}}$ & 16 & 44 & 175 & $17.8^{\mathrm{C}}$ \\
\hline MA & 59 & 226 & 283 & 1.4 & 469 & 746 & 59 & $1.2^{\mathrm{C}}$ & 133 & 955 & 618 & $3.8^{c}$ & 52 & 93 & 79 & 2.8 \\
\hline ME & 169 & 485 & 187 & $2.2^{\mathrm{c}}$ & 327 & 620 & 90 & $2.8^{\mathrm{C}}$ & 273 & 1,360 & 398 & $3.1^{\mathrm{c}}$ & 42 & 144 & 243 & $7.6^{\mathrm{C}}$ \\
\hline $\mathrm{NH}$ & 157 & 622 & 296 & $2.3^{c}$ & 480 & 1,381 & 188 & $3.0^{c}$ & 218 & 1,569 & 620 & $3.9^{\mathrm{c}}$ & 84 & 149 & 77 & $5.7^{c}$ \\
\hline NJ & 45 & 320 & 611 & $3.3^{c}$ & 702 & 824 & 17 & $1.3^{\mathrm{C}}$ & 169 & 1,505 & 791 & $3.7^{c}$ & 50 & 74 & 48 & $11.7^{\mathrm{C}}$ \\
\hline NY & 50 & 234 & 368 & $2.5^{\mathrm{c}}$ & 372 & 768 & 106 & $1.9^{c}$ & 120 & 1,059 & 783 & $3.7^{\mathrm{c}}$ & 45 & 35 & -22 & $3.6^{c}$ \\
\hline PA & 69 & 305 & 342 & $2.0^{c}$ & 349 & 350 & 0 & 0 & 198 & 972 & 391 & $2.8^{\mathrm{C}}$ & 47 & 81 & 72 & $8.7^{\mathrm{c}}$ \\
\hline $\mathrm{RI}$ & 66 & 226 & 242 & $2.1^{\mathrm{c}}$ & 376 & 427 & 14 & 1.0 & 208 & 859 & 313 & $2.8^{\mathrm{C}}$ & 40 & 120 & 200 & $19.4^{c}$ \\
\hline VT & 147 & 143 & -3 & 0.1 & 101 & 460 & 355 & $4.7^{\mathrm{C}}$ & 58 & 636 & 997 & $4.6^{c}$ & 12 & 60 & 400 & $11.7^{\mathrm{C}}$ \\
\hline
\end{tabular}

\section{Midwest}

\begin{tabular}{|c|c|c|c|c|c|c|c|c|c|c|c|c|c|c|c|c|}
\hline IA & 36 & 189 & 425 & 3 & 258 & 312 & 21 & 1.4 & 90 & 580 & 544 & $3.8^{\mathrm{c}}$ & 14 & 34 & 143 & $11.8^{\mathrm{C}}$ \\
\hline IL & 151 & 225 & 49 & 1.3 & 288 & 1,527 & 430 & $3.6^{\mathrm{c}}$ & 239 & 740 & 210 & $2.7^{\mathrm{C}}$ & 34 & 110 & 224 & $8.0^{c}$ \\
\hline IN & 162 & 306 & 89 & 0.8 & 219 & 241 & 10 & 0.8 & 268 & 770 & 187 & $2.1^{\mathrm{c}}$ & 42 & 63 & 50 & 0.8 \\
\hline KS & 65 & 225 & 246 & $2.5^{\mathrm{c}}$ & 275 & 183 & -33 & -0.8 & 232 & 475 & 105 & $1.6^{\mathrm{c}}$ & 44 & 62 & 41 & $11.1^{\mathrm{C}}$ \\
\hline $\mathrm{MI}$ & 75 & 369 & 392 & $2.3^{\mathrm{c}}$ & 198 & 218 & 10 & $1.4^{c}$ & 106 & 1,015 & 858 & $4.3^{c}$ & 26 & 69 & 165 & $13.0^{c}$ \\
\hline MN & 9 & 45 & 400 & 3.5 & 168 & 169 & 1 & $3.2^{c}$ & 12 & 127 & 958 & $5.2^{c}$ & 11 & 81 & 636 & $15.3^{c}$ \\
\hline MO & 134 & 226 & 69 & 1.2 & 301 & 333 & 11 & $1.2^{c}$ & 311 & 585 & 88 & $1.3^{\mathrm{c}}$ & 29 & 50 & 72 & $5.5^{\mathrm{c}}$ \\
\hline ND & 35 & 44 & 26 & -1.6 & 105 & 454 & 332 & $3.5^{c}$ & 44 & 123 & 180 & $2.4^{\mathrm{c}}$ & 11 & 17 & 55 & $7.1^{\mathrm{c}}$ \\
\hline NE & 101 & 322 & 219 & 2.1 & 307 & 371 & 21 & $1.9^{c}$ & 326 & 896 & 175 & $2.1^{\mathrm{c}}$ & 150 & 85 & -43 & -3.4 \\
\hline $\mathrm{OH}$ & 172 & 458 & 166 & 1.3 & 279 & 303 & 9 & $1.4^{c}$ & 227 & 1,259 & 455 & $3.1^{\mathrm{c}}$ & 41 & 80 & 95 & $14.0^{c}$ \\
\hline SD & 21 & 254 & 1,110 & $5.1^{\mathrm{c}}$ & 131 & 442 & 237 & $3.7^{c}$ & 38 & 1,641 & 4,218 & $6.8^{c}$ & 12 & 15 & 25 & $6.6^{c}$ \\
\hline WI & 136 & 173 & 27 & -0.1 & 170 & 336 & 98 & $1.7^{\mathrm{c}}$ & 197 & 870 & 342 & $2.6^{\mathrm{c}}$ & 44 & 97 & 120 & $14.0^{c}$ \\
\hline \multicolumn{17}{|c|}{ South } \\
\hline $\mathrm{AL}$ & 458 & 326 & -29 & -0.6 & 753 & 489 & -35 & -0.1 & 514 & 1,098 & 114 & $1.5^{\mathrm{c}}$ & 116 & 125 & 8 & $1.1^{\mathrm{c}}$ \\
\hline AR & 135 & 269 & 99 & 2.0 & 436 & 464 & 6 & 0.8 & 313 & 796 & 154 & $1.6^{c}$ & 57 & 58 & 2 & 2.1 \\
\hline$D C$ & 13 & 50 & 285 & $2.2^{\mathrm{c}}$ & 76 & 144 & 89 & $2.9^{c}$ & 30 & 133 & 343 & $3.0^{c}$ & 8 & 23 & 188 & $11.0^{c}$ \\
\hline
\end{tabular}

Abbreviation: AMPC, average monthly percentage change.

${ }^{a}$ Average monthly unit sales. Equivalent sales per 100,000 people; 1 unit is equal to 1 rechargeable or 1 disposable e-cigarette, 1 pack of 5 prefilled cartridges, or 1 bottle of e-liquid.

${ }^{\mathrm{b}}$ AMPC is average percentage change per 4-week period. For rechargeables, disposables, and prefilled cartridges, calculations included all periods from 2012 through $2016(n=65)$. For e-liquids, calculations included all periods from 2014 through 2016 with non-zero sales.

${ }^{c}$ Indicates significant change $(\alpha=.05)$.

${ }^{\mathrm{d}}$ No e-liquid sales were reported in the data until mid-2013. Percentage change reflects change from 2014 to 2016. 
(continued)

Table 1. E-Cigarette Unit Sales by Product Type, United States, 2012-2016

\begin{tabular}{|c|c|c|c|c|c|c|c|c|c|c|c|c|c|c|c|c|}
\hline \multirow[b]{3}{*}{ State } & \multicolumn{4}{|c|}{ Rechargeables } & \multicolumn{4}{|c|}{ Disposables } & \multicolumn{4}{|c|}{ Prefilled Cartridges } & \multicolumn{4}{|c|}{ E-Liquids } \\
\hline & \multicolumn{2}{|c|}{$\begin{array}{l}\text { Monthly Unit } \\
\text { Sales }\end{array}$} & \multirow{2}{*}{$\begin{array}{c}\text { Change, } \\
\%\end{array}$} & \multirow[b]{2}{*}{$\mathrm{AMPC}^{\mathrm{b}}$} & \multicolumn{2}{|c|}{$\begin{array}{l}\text { Monthly Unit } \\
\text { Sales }\end{array}$} & \multirow{2}{*}{$\begin{array}{c}\text { Change, } \\
\%\end{array}$} & \multirow[b]{2}{*}{$\mathrm{AMPC}^{\mathrm{b}}$} & \multicolumn{2}{|c|}{$\begin{array}{l}\text { Monthly Unit } \\
\text { Sales }\end{array}$} & \multirow{2}{*}{$\begin{array}{c}\text { Change, } \\
\%\end{array}$} & \multirow[b]{2}{*}{ AMPC $^{b}$} & \multicolumn{2}{|c|}{$\begin{array}{l}\text { Monthly Unit } \\
\text { Sales }\end{array}$} & \multirow{2}{*}{ Change, } & \multirow[b]{2}{*}{$\mathrm{AMPC}^{\mathrm{b}}$} \\
\hline & 2012 & 2016 & & & 2012 & 2016 & & & 2012 & 2016 & & & 2014 & 2016 & & \\
\hline DE & 35 & 200 & 471 & $2.0^{c}$ & 239 & 333 & 39 & $1.3^{\mathrm{c}}$ & 102 & 662 & 549 & $3.9^{c}$ & 25 & 63 & 152 & $10.5^{\mathrm{C}}$ \\
\hline $\mathrm{FL}$ & 90 & 335 & 272 & $2.4^{c}$ & 591 & 634 & 7 & $0.9^{c}$ & 160 & 809 & 406 & $3.4^{c}$ & 58 & 99 & 71 & $22.4^{c}$ \\
\hline GA & 242 & 334 & 38 & 0.4 & 460 & 374 & -19 & 0.5 & 544 & 832 & 53 & $0.7^{\mathrm{c}}$ & 92 & 92 & 0 & 0 \\
\hline KY & 234 & 445 & 90 & 0.5 & 234 & 254 & 9 & 0.4 & 489 & 945 & 93 & $1.3^{\mathrm{c}}$ & 53 & 120 & 126 & $5.5^{c}$ \\
\hline LA & 106 & 182 & 72 & 0.6 & 525 & 238 & -55 & -0.8 & 229 & 555 & 142 & $1.4^{c}$ & 29 & 45 & 55 & $7.1^{c}$ \\
\hline MD & 38 & 227 & 497 & $3.2^{c}$ & 224 & 346 & 54 & 1.4 & 111 & 742 & 568 & $3.6^{c}$ & 41 & 67 & 63 & $20.2^{c}$ \\
\hline MS & 303 & 229 & -24 & -0.3 & 729 & 389 & -47 & -0.5 & 825 & 680 & -18 & -0.1 & 44 & 181 & 311 & $11.3^{c}$ \\
\hline NC & 136 & 254 & 87 & 1.4 & 564 & 334 & -41 & 0 & 243 & 863 & 255 & $2.6^{\mathrm{c}}$ & 79 & 66 & -16 & $2.7^{\mathrm{C}}$ \\
\hline OK & 117 & 184 & 57 & 0.9 & 274 & 220 & -20 & 0.1 & 330 & 552 & 67 & $0.9^{c}$ & 40 & 63 & 58 & $6.8^{c}$ \\
\hline SC & 179 & 327 & 83 & 0.9 & 804 & 321 & -60 & -0.3 & 497 & 875 & 76 & 0.6 & 133 & 116 & -13 & $3.6^{c}$ \\
\hline TN & 235 & 207 & -12 & -0.2 & 509 & 324 & -36 & -0.3 & 569 & 583 & 2 & 0.7 & 44 & 87 & 98 & $5.9^{c}$ \\
\hline TX & 70 & 242 & 246 & 1.8 & 328 & 271 & -17 & -0.3 & 161 & 495 & 207 & $2.2^{\mathrm{c}}$ & 25 & 56 & 124 & $13.7^{\mathrm{C}}$ \\
\hline VA & 108 & 282 & 161 & 1.4 & 409 & 346 & -15 & 0.6 & 407 & 724 & 78 & $1.1^{\mathrm{c}}$ & 96 & 138 & 44 & $14.0^{c}$ \\
\hline WV & 298 & 530 & 78 & 1.2 & 276 & 785 & 184 & 0.9 & 527 & 1,173 & 123 & $1.7^{\mathrm{c}}$ & 211 & 258 & 22 & $13.9^{c}$ \\
\hline \multicolumn{17}{|l|}{ West } \\
\hline$A Z$ & 77 & 205 & 166 & $1.7^{\mathrm{C}}$ & 230 & 384 & 67 & $1.1^{\mathrm{c}}$ & 145 & 454 & 213 & $2.2^{c}$ & 75 & 96 & 28 & $6.2^{c}$ \\
\hline \begin{tabular}{|l}
$\mathrm{CA}$ \\
\end{tabular} & 35 & 151 & 331 & $2.2^{\mathrm{c}}$ & 168 & 308 & 83 & $1.7^{\mathrm{c}}$ & 49 & 431 & 780 & $4.0^{c}$ & 14 & 42 & 200 & $13.3^{c}$ \\
\hline CO & 57 & 319 & 460 & $3.0^{c}$ & 235 & 224 & -5 & 0.8 & 115 & 1,038 & 803 & $3.9^{c}$ & 57 & 82 & 44 & $5.5^{c}$ \\
\hline ID & 90 & 344 & 282 & $2.6^{c}$ & 191 & 287 & 50 & 0.5 & 344 & 691 & 101 & $2.1^{c}$ & 50 & 80 & 60 & $10.6^{c}$ \\
\hline MT & 32 & 112 & 250 & 2.4 & 231 & 327 & 42 & $4.3^{c}$ & 144 & 255 & 77 & $2.8^{\mathrm{c}}$ & 18 & 62 & 244 & $8.3^{c}$ \\
\hline NM & 104 & 133 & 28 & 0.4 & 242 & 237 & -2 & 0.3 & 169 & 252 & 49 & $1.3^{\mathrm{c}}$ & 88 & 92 & 5 & 0.2 \\
\hline NV & 61 & 349 & 472 & $2.3^{c}$ & 512 & 774 & 51 & 0.4 & 115 & 1,030 & 796 & $2.8^{\mathrm{C}}$ & 76 & 131 & 72 & $7.5^{\mathrm{c}}$ \\
\hline OR & 73 & 246 & 237 & $1.9^{c}$ & 273 & 328 & 20 & 0 & 95 & 699 & 636 & $3.6^{c}$ & 45 & 93 & 107 & $8.8^{c}$ \\
\hline UT & 188 & 370 & 97 & 1 & 214 & 287 & 34 & -1.2 & 895 & 1,229 & 37 & 0.8 & 85 & 203 & 139 & $15.7^{c}$ \\
\hline WA & 35 & 248 & 609 & $2.4^{\mathrm{c}}$ & 269 & 326 & 21 & 1 & 118 & 677 & 474 & $3.5^{c}$ & 45 & 71 & 58 & $9.4^{c}$ \\
\hline WY & 45 & 44 & -2 & -0.3 & 92 & 93 & 1 & 0.4 & 158 & 147 & -7 & 0.1 & 11 & 20 & 82 & $5.6^{c}$ \\
\hline
\end{tabular}

Abbreviation: AMPC, average monthly percentage change.

${ }^{a}$ Average monthly unit sales. Equivalent sales per 100,000 people; 1 unit is equal to 1 rechargeable or 1 disposable e-cigarette, 1 pack of 5 prefilled cartridges, or 1 bottle of e-liquid.

${ }^{\mathrm{b}}$ AMPC is average percentage change per 4-week period. For rechargeables, disposables, and prefilled cartridges, calculations included all periods from 2012 through $2016(n=65)$. For e-liquids, calculations included all periods from 2014 through 2016 with non-zero sales.

${ }^{c}$ Indicates significant change $(\alpha=.05)$.

${ }^{d}$ No e-liquid sales were reported in the data until mid-2013. Percentage change reflects change from 2014 to 2016. 
Table 2. Average E-Cigarette Prices by Product Type, United States, 2012-2016

\begin{tabular}{|c|c|c|c|c|c|c|c|c|c|c|c|c|c|c|c|c|}
\hline \multirow[b]{3}{*}{ State } & \multicolumn{4}{|c|}{ Rechargeables } & \multicolumn{4}{|c|}{ Disposables } & \multicolumn{4}{|c|}{ Prefilled Cartridges } & \multicolumn{4}{|c|}{ E-Liquids } \\
\hline & \multicolumn{2}{|c|}{$\begin{array}{l}\text { Average } \\
\text { Price, } \$^{a}\end{array}$} & \multirow{2}{*}{$\begin{array}{c}\text { Change, } \\
\%\end{array}$} & \multirow[b]{2}{*}{ AMPC $^{b}$} & \multicolumn{2}{|c|}{$\begin{array}{l}\text { Average } \\
\text { Price, } \$^{a}\end{array}$} & \multirow{2}{*}{$\begin{array}{c}\text { Change, } \\
\%\end{array}$} & \multirow[b]{2}{*}{$\mathrm{AMPC}^{\mathrm{b}}$} & \multicolumn{2}{|c|}{$\begin{array}{l}\text { Average } \\
\text { Price, } \$^{a}\end{array}$} & \multirow{2}{*}{$\begin{array}{c}\text { Change, } \\
\%\end{array}$} & \multirow[b]{2}{*}{ AMPC $^{b}$} & \multicolumn{2}{|c|}{$\begin{array}{l}\text { Average } \\
\text { Price, } \$^{a}\end{array}$} & \multirow{2}{*}{$\begin{array}{c}\text { Change, } \\
\%^{\mathrm{d}}\end{array}$} & \multirow[b]{2}{*}{$\mathrm{AMPC}^{\mathrm{b}}$} \\
\hline & 2012 & 2016 & & & 2012 & 2016 & & & 2012 & 2016 & & & 2014 & 2016 & & \\
\hline All & 19.81 & 10.33 & -48 & $-1.2^{c}$ & 9.29 & 8.01 & -14 & $-0.2^{c}$ & 16.37 & 14.36 & -12 & $-0.4^{c}$ & 7.51 & 6.83 & -9 & -0.1 \\
\hline \multicolumn{17}{|c|}{ Northeast } \\
\hline CT & 26.23 & 12.51 & -52 & $-1.3^{c}$ & 10.01 & 9.52 & -5 & -0.1 & 15.89 & 18.04 & 14 & 0.1 & 7.72 & 7.45 & -3 & -0.1 \\
\hline MA & 23.78 & 10.45 & -56 & $-1.5^{c}$ & 10.12 & 9.39 & -7 & $-0.1^{c}$ & 16.29 & 16.82 & 3 & -0.2 & 7.88 & 6.38 & -19 & $-0.9^{\mathrm{C}}$ \\
\hline ME & 18.36 & 10.14 & -45 & $-1.2^{c}$ & 10.22 & 9.20 & -10 & $-0.4^{c}$ & 14.91 & 15.17 & 2 & -0.2 & 7.60 & 6.52 & -14 & -1.1 \\
\hline $\mathrm{NH}$ & 18.79 & 9.74 & -48 & $-1.4^{c}$ & 9.84 & 8.68 & -12 & $-0.3^{c}$ & 15.05 & 16.61 & 10 & 0.1 & 7.38 & 7.40 & 0 & 0 \\
\hline NJ & 28.00 & 9.15 & -67 & $-1.8^{c}$ & 9.80 & 8.95 & -9 & -0.1 & 18.95 & 16.62 & -12 & $-0.4^{c}$ & 7.69 & 6.94 & -10 & 0.3 \\
\hline NY & 23.12 & 10.15 & -56 & $-1.7^{\mathrm{C}}$ & 9.51 & 9.16 & -4 & 0 & 19.05 & 15.02 & -21 & $-0.9^{\mathrm{c}}$ & 7.60 & 6.40 & -16 & -0.1 \\
\hline PA & 23.76 & 11.31 & -52 & -0.7 & 9.04 & 8.70 & -4 & $0.3^{c}$ & 16.63 & 13.28 & -20 & $-0.4^{c}$ & 7.54 & 6.90 & -8 & 0 \\
\hline RI & 23.23 & 11.30 & -51 & $-1.1^{\mathrm{c}}$ & 9.50 & 9.22 & -3 & 0 & 17.82 & 15.96 & -10 & $-0.8^{\mathrm{c}}$ & 8.10 & 7.18 & -11 & $-1.0^{c}$ \\
\hline VT & 13.91 & 12.01 & -14 & $-1.0^{c}$ & 9.28 & 9.09 & -2 & -0.3 & 15.35 & 15.17 & -1 & -0.3 & 7.22 & 5.54 & -23 & -0.5 \\
\hline \multicolumn{17}{|c|}{ Midwest } \\
\hline IA & 26.64 & 12.15 & -54 & $-1.5^{c}$ & 9.37 & 8.43 & -10 & $-0.2^{c}$ & 16.90 & 15.03 & -11 & $-0.2^{c}$ & 7.60 & 7.98 & 5 & 0.5 \\
\hline IL & 20.29 & 11.82 & -42 & -0.4 & 9.85 & 6.20 & -37 & $-0.8^{c}$ & 16.36 & 14.72 & -10 & $-0.3^{c}$ & 8.05 & 7.06 & -12 & $-0.5^{\mathrm{c}}$ \\
\hline IN & 18.16 & 9.78 & -46 & $-1.0^{c}$ & 9.60 & 8.12 & -15 & $-0.3^{c}$ & 15.84 & 15.18 & -4 & 0 & 8.24 & 7.97 & -3 & 0.3 \\
\hline KS & 25.44 & 8.93 & -65 & $-1.7^{\mathrm{C}}$ & 9.27 & 8.26 & -11 & -0.2 & 16.93 & 15.81 & -7 & 0 & 7.53 & 6.85 & -9 & 0.3 \\
\hline $\mathrm{MI}$ & 17.32 & 9.78 & -44 & $-1.1^{\mathrm{C}}$ & 9.09 & 7.37 & -19 & $-0.4^{c}$ & 15.67 & 11.87 & -24 & $-0.6^{c}$ & 7.36 & 6.45 & -12 & -0.1 \\
\hline MN & 22.35 & 15.00 & -33 & -0.7 & 10.97 & 11.20 & 2 & 0.2 & 23.14 & 17.12 & -26 & 0.4 & 7.16 & 7.91 & 10 & 0.5 \\
\hline MO & 21.58 & 12.12 & -44 & -0.7 & 9.28 & 8.17 & -12 & $-0.2^{c}$ & 15.95 & 13.58 & -15 & $-0.2^{c}$ & 7.93 & 7.45 & -6 & -0.3 \\
\hline ND & 28.21 & 12.71 & -55 & -1.1 & 8.88 & 7.99 & -10 & 0.1 & 16.76 & 13.23 & -21 & $-0.6^{c}$ & 7.24 & 7.39 & 2 & 0.6 \\
\hline NE & 22.23 & 12.13 & -45 & -0.7 & 9.24 & 8.20 & -11 & $-0.2^{c}$ & 15.40 & 12.83 & -17 & -0.3 & 7.95 & 7.09 & -11 & 0.1 \\
\hline $\mathrm{OH}$ & 17.56 & 9.81 & -44 & $-1.0^{c}$ & 9.05 & 8.08 & -11 & $-0.4^{c}$ & 16.05 & 13.94 & -13 & -0.2 & 7.01 & 7.51 & 7 & -0.1 \\
\hline SD & 31.85 & 12.06 & -62 & $-1.4^{c}$ & 8.97 & 8.03 & -10 & $-0.3^{c}$ & 16.12 & 15.56 & -3 & 0.2 & 7.19 & 8.44 & 17 & 1.4 \\
\hline WI & 17.62 & 12.83 & -27 & -0.4 & 9.82 & 7.58 & -23 & $-0.4^{c}$ & 15.84 & 16.39 & 3 & $0.2^{c}$ & 6.90 & 7.30 & 6 & 0.4 \\
\hline \multicolumn{17}{|l|}{ South } \\
\hline $\mathrm{AL}$ & 15.90 & 10.99 & -31 & $-0.8^{c}$ & 9.43 & 7.49 & -21 & $-0.4^{c}$ & 16.31 & 12.18 & -25 & $-0.5^{c}$ & 6.65 & 5.32 & -20 & -0.4 \\
\hline AR & 18.06 & 11.93 & -34 & $-1.1^{c}$ & 8.86 & 7.95 & -10 & -0.1 & 15.91 & 13.49 & -15 & 0.1 & 6.03 & 6.68 & 11 & $0.4^{c}$ \\
\hline DC & 28.20 & 18.43 & -35 & -0.5 & 9.64 & 14.75 & 53 & $0.7^{c}$ & 18.85 & 20.58 & 9 & -0.2 & 7.88 & 10.19 & 29 & $1.6^{\mathrm{c}}$ \\
\hline DE & 27.80 & 10.17 & -63 & $-1.7^{c}$ & 9.93 & 8.22 & -17 & $-0.4^{c}$ & 15.73 & 16.04 & 2 & 0 & 6.78 & 6.95 & 3 & 0.2 \\
\hline $\mathrm{FL}$ & 19.29 & 9.77 & -49 & $-1.2^{c}$ & 9.40 & 8.25 & -12 & $-0.3^{c}$ & 19.13 & 14.38 & -25 & $-0.8^{c}$ & 7.60 & 7.31 & -4 & $0.8^{\mathrm{c}}$ \\
\hline GA & 17.47 & 10.43 & -40 & $-1.1^{c}$ & 9.03 & 8.53 & -6 & $-0.1^{c}$ & 15.87 & 14.54 & -8 & -0.1 & 7.62 & 6.92 & -9 & $-0.4^{c}$ \\
\hline
\end{tabular}

${ }^{\text {a }}$ Average price per unit; 1 unit is equal to 1 rechargeable or 1 disposable e-cigarette, 1 pack of 5 prefilled cartridges, or 1 bottle of e-liquid.

${ }^{\mathrm{b}}$ AMPC is the average monthly percentage change, or the average percentage change per 4-week period. For rechargeables, disposables, and prefilled cartridges, calculations included all periods from 2012 through $2016(n=65)$. For e-liquids, calculations included all periods from 2014 through 2016 with non-zero sales. ${ }^{\mathrm{c}}$ Indicates significant change $(\alpha=.05)$.

${ }^{d}$ No e-liquid sales were reported in the data until mid-2013. Percentage change reflects change from 2014 to 2016. 
(continued)

Table 2. Average E-Cigarette Prices by Product Type, United States, 2012-2016

\begin{tabular}{|c|c|c|c|c|c|c|c|c|c|c|c|c|c|c|c|c|}
\hline \multirow[b]{3}{*}{ State } & \multicolumn{4}{|c|}{ Rechargeables } & \multicolumn{4}{|c|}{ Disposables } & \multicolumn{4}{|c|}{ Prefilled Cartridges } & \multicolumn{4}{|c|}{ E-Liquids } \\
\hline & \multicolumn{2}{|c|}{$\begin{array}{l}\text { Average } \\
\text { Price, } \$\end{array}$} & \multirow{2}{*}{$\underset{\%}{\text { Change, }}$} & \multirow[b]{2}{*}{$\mathrm{AMPC}^{\mathrm{b}}$} & \multicolumn{2}{|c|}{$\begin{array}{l}\text { Average } \\
\text { Price, } \$^{a}\end{array}$} & \multirow{2}{*}{$\begin{array}{c}\text { Change, } \\
\%\end{array}$} & \multirow[b]{2}{*}{ AMPC $^{b}$} & \multicolumn{2}{|c|}{$\begin{array}{l}\text { Average } \\
\text { Price, } \$\end{array}$} & \multirow{2}{*}{ Change, } & \multirow[b]{2}{*}{$\mathrm{AMPC}^{\mathrm{b}}$} & \multicolumn{2}{|c|}{$\begin{array}{l}\text { Average } \\
\text { Price, } \${ }^{a}\end{array}$} & \multirow{2}{*}{$\begin{array}{c}\text { Change, } \\
\%^{\mathrm{d}}\end{array}$} & \multirow[b]{2}{*}{$\mathrm{AMPC}^{\mathrm{b}}$} \\
\hline & 2012 & 2016 & & & 2012 & 2016 & & & 2012 & 2016 & & & 2014 & 2016 & & \\
\hline KY & 17.81 & 9.35 & -47 & $-1.5^{c}$ & 9.39 & 8.12 & -14 & $-0.2^{\mathrm{C}}$ & 15.26 & 13.96 & -9 & 0.1 & 7.93 & 7.36 & -7 & $-0.6^{c}$ \\
\hline LA & 22.36 & 10.98 & -51 & $-1.3^{\mathrm{c}}$ & 9.41 & 8.04 & -15 & $-0.3^{c}$ & 16.19 & 11.90 & -26 & $-0.5^{c}$ & 6.00 & 7.95 & 33 & $3.3^{\mathrm{c}}$ \\
\hline MD & 25.65 & 9.55 & -63 & $-1.7^{\mathrm{c}}$ & 8.92 & 7.87 & -12 & -0.1 & 17.60 & 15.14 & -14 & $-0.5^{c}$ & 8.38 & 6.67 & -20 & -0.9 \\
\hline MS & 19.51 & 10.76 & -45 & $-1.4^{\mathrm{c}}$ & 9.13 & 7.81 & -14 & $-0.3^{c}$ & 16.07 & 13.36 & -17 & -0.2 & 7.93 & 5.70 & -28 & $-1.7^{\mathrm{c}}$ \\
\hline $\mathrm{NC}$ & 19.02 & 10.87 & -43 & $-1.1^{\mathrm{c}}$ & 9.06 & 7.58 & -16 & -0.2 & 15.88 & 12.84 & -19 & -0.3 & 7.35 & 6.90 & -6 & -0.1 \\
\hline OK & 19.39 & 11.78 & -39 & $-1.1^{\mathrm{c}}$ & 9.20 & 8.14 & -12 & $-0.2^{c}$ & 14.91 & 10.43 & -30 & $-0.6^{c}$ & 7.36 & 6.78 & -8 & 0.2 \\
\hline SC & 19.31 & 10.70 & -45 & $-1.3^{c}$ & 8.90 & 8.33 & -6 & -0.2 & 15.99 & 12.43 & -22 & $-0.6^{c}$ & 6.60 & 6.48 & -2 & 0 \\
\hline TN & 19.16 & 11.96 & -38 & $-1.0^{c}$ & 9.16 & 7.63 & -17 & $-0.4^{c}$ & 15.69 & 13.80 & -12 & 0 & 7.74 & 6.00 & -22 & $-0.8^{c}$ \\
\hline TX & 19.76 & 8.73 & -56 & $-1.5^{c}$ & 9.20 & 7.97 & -13 & $-0.2^{c}$ & 16.67 & 12.20 & -27 & -0.2 & 7.82 & 6.84 & -13 & $0.7^{\mathrm{c}}$ \\
\hline VA & 22.46 & 8.87 & -61 & $-1.7^{c}$ & 8.73 & 7.90 & -10 & $-0.3^{c}$ & 17.37 & 12.88 & -26 & $-0.7^{c}$ & 7.33 & 6.47 & -12 & 1.1 \\
\hline WV & 15.88 & 8.38 & -47 & $-1.7^{\mathrm{c}}$ & 9.12 & 6.51 & -29 & -0.3 & 15.89 & 11.39 & -28 & $-0.6^{c}$ & 6.94 & 6.34 & -9 & -0.9 \\
\hline \multicolumn{17}{|l|}{ West } \\
\hline$A Z$ & 21.99 & 11.62 & -47 & $-1.0^{c}$ & 9.59 & 7.64 & -20 & $-0.4^{c}$ & 16.08 & 15.08 & -6 & 0.1 & 8.00 & 7.26 & -9 & $-0.4^{c}$ \\
\hline CA & 23.26 & 11.78 & -49 & $-0.6^{c}$ & 8.99 & 8.05 & -10 & $-0.3^{c}$ & 17.53 & 13.97 & -20 & $-0.4^{c}$ & 7.43 & 6.98 & -6 & 0.1 \\
\hline $\mathrm{CO}$ & 26.58 & 10.10 & -62 & $-1.5^{c}$ & 9.38 & 8.20 & -13 & $-0.2^{c}$ & 15.74 & 12.68 & -19 & $-0.7^{\mathrm{c}}$ & 7.64 & 7.22 & -5 & 0.2 \\
\hline ID & 22.17 & 9.17 & -59 & $-1.8^{c}$ & 9.17 & 7.71 & -16 & $-0.4^{c}$ & 15.43 & 16.09 & 4 & 0.3 & 6.89 & 6.29 & -9 & 0.1 \\
\hline MT & 25.94 & 11.54 & -56 & -1.3 & 8.87 & 6.82 & -23 & $-0.6^{c}$ & 15.70 & 13.83 & -12 & 0.3 & 6.14 & 5.34 & -13 & 0 \\
\hline NM & 19.70 & 10.53 & -47 & $-1.3^{c}$ & 9.61 & 7.84 & -18 & $-0.3^{c}$ & 15.24 & 15.42 & 1 & 0.2 & 7.96 & 7.07 & -11 & 0 \\
\hline NV & 24.38 & 11.93 & -51 & $-1.0^{c}$ & 8.83 & 7.60 & -14 & -0.1 & 16.44 & 14.77 & -10 & 0 & 7.72 & 6.96 & -10 & -0.4 \\
\hline OR & 23.14 & 11.09 & -52 & -0.6 & 9.07 & 7.89 & -13 & -0.1 & 15.72 & 15.43 & -2 & -0.1 & 7.42 & 6.36 & -14 & 0.4 \\
\hline UT & 20.69 & 9.43 & -54 & $-1.5^{c}$ & 8.70 & 6.70 & -23 & $-0.4^{c}$ & 14.34 & 13.00 & -9 & $-0.2^{c}$ & 7.63 & 6.04 & -21 & -0.5 \\
\hline WA & 25.48 & 10.04 & -61 & $-1.3^{\mathrm{c}}$ & 8.86 & 7.81 & -12 & -0.2 & 16.05 & 14.88 & -7 & 0 & 7.19 & 6.67 & -7 & 0.5 \\
\hline WY & 28.40 & 13.21 & -53 & $-1.2^{\mathrm{C}}$ & 9.51 & 8.19 & -14 & $-0.3^{c}$ & 15.01 & 15.76 & 5 & $0.2^{c}$ & 7.34 & 8.16 & 11 & $1.2^{\mathrm{C}}$ \\
\hline
\end{tabular}

${ }^{\text {a }}$ Average price per unit; 1 unit is equal to 1 rechargeable or 1 disposable e-cigarette, 1 pack of 5 prefilled cartridges, or 1 bottle of e-liquid.

${ }^{\mathrm{b}}$ AMPC is the average monthly percentage change, or the average percentage change per 4-week period. For rechargeables, disposables, and prefilled cartridges, calculations included all periods from 2012 through $2016(n=65)$. For e-liquids, calculations included all periods from 2014 through 2016 with non-zero sales.

${ }^{\mathrm{C}}$ Indicates significant change $(\alpha=.05)$.

${ }^{d}$ No e-liquid sales were reported in the data until mid-2013. Percentage change reflects change from 2014 to 2016. 